\title{
PALESTINE: UMA PERSPECTIVA INTEGRADA NO PROCESSO DE PRODUÇÃO DA HISTÓRIA EM QUADRINHO DE JOE SACCO (1993-1995)
}

\author{
José Rodolfo Vieira (História Social - UEL) \\ Prof.Dr. Rochard Gonçalves André (Orientador)
}

\section{RESUMO}

Por meio deste trabalho, tentaremos observar as táticas e estratégias utilizadas por Joe Sacco na produção da história em quadrinhos Palestine por meio da perspectiva Integrada do semioticista italiano Umberto Eco. Palestine é resultado da viagem do jornalista Sacco aos territórios ocupados por Israel após a guerra de 1967. Em dezembro de 1991, após três anos do início do levante popular Intifada na Palestina, Sacco, por conta própria realiza a cobertura dos acontecimentos, e, de maneira inovadora em sua narrativa, relata os fatos em forma de quadrinhos. Portanto, nos pautaremos por meios metodológicos, tal como Will Eisner e Peter Burke observarmos as estratégias utilizadas por Sacco na produção e interação com seu leitor. Além disso, observaremos as leituras realizadas por ele desde 1981 que construíram seu campo tático que resultou na produção de Palestine. Portanto, por meio da análise destas táticas e estratégias tentaremos observar de que forma um novo meio de produção simbólico surge de forma rebelde dentro de um campo simbólico estruturado

\section{APRESENTAÇÃO}

O objetivo de nosso trabalho é compreender a produção da história em quadrinhos Palestine de Joe Sacco, por meio da perspectiva de Indústria Cultural discutida por Umberto Eco (s.d.) como uma visão Integrada da cultura de massa. Para tanto, consideramos os dizeres de Eco (s.d, p.34) de que o advento da era industrial e o acesso da classe subalterna ao controle da vida associada estabeleceram as bases do mass media, e assim, este novo sistema de valores deve ser discutido. Portanto, visamos aqui compreender a produção de Palestine dentro desse novo sistema de valores inseridos dentro das táticas e estratégias de sua produção.

Para tanto, devemos compreender que seu criador estabelece uma relação com seus leitores durante o processo de produção. O trabalho de Will Eisner (2010) nos servirá de guia para percebermos estas táticas e estratégias estabelecidas dentro do campo de produção cultural das histórias em quadrinhos. Além disso, Peter Burke (2004) contribuirá na compreensão do papel do criador como um "repórter não inocente", pois, como testemunha ocular de um recorte temporal, sua produção também está inserida dentro de um campo de subjetividade.

Sobre as táticas e estratégias, nos baseamos na noção de Michel de Certeau (1998). Em sua perspectiva, os agentes históricos não assimilam qualquer produto sem nenhum questionamento. $\mathrm{O}$ consumo e as práticas cotidianas estão totalmente permeados por escolhas conforme suas necessidades. No entanto, a análise não se baseia somente no consumo, mas também, colabora no entendimento do processo fabricação de um produto 


\section{SEMINÁRIO DE PESQUISA EM CIÊNCIAS HUMANAS - SEPECH \\ Humanidades, Estado e desafios didático-científicos \\ Londrina, 27 a 29 de julho de 2016}

consumível. Por meio da noção de táticas e estratégias, tentaremos compreender as escolhas de Sacco na produção de Palestine.

Portanto, por meio destas ferramentas, temos como objetivo analisar o processo de produção de Palestine. Assim sendo, observaremos o jogo dinâmico de táticas e estratégias para assim, observarmos que dentro de um produto já pronto para consumo, outros consumos e práticas foram aplicados para sua produção como produto da Indústria Cultural.

\section{UMBERTO ECO: UMA NOVA VISÃO SOBRE A INDÚSTRIA CULTURAL}

A visão de Eco (s.d.) sobre a Indústria Cultural possibilita uma perspectiva de análise mais otimista sobre estes novos meios de comunicação em massa. Em sua análise, Eco (s.d.) lança dentro da discussão sobre a Indústria Cultural uma visão revisionista, ao retornar aos canônicos autores da Indústria Cultural, junto de um novo olhar positivo. Para tanto, Eco (s.d.) separa em dois conjuntos os olhares voltados para a Indústria Cultural. Estes dois conjuntos de pensadores, ou de perspectivas sobre os meios de comunicação em massa, foram designados por ele como Apocalípticos e Integrados. Não podemos nos esquecer que para Eco (s.d.) estas duas faces não correspondem a uma oposição entre atitudes, mas sim, em termos complementares e adaptáveis a uma crítica popular da cultura popular. Segundo Eco (s.d., p.9)

Mas até que ponto não nos encontramos ante duas faces de um mesmo
problema, e não representarão esses textos apocalípticos o mais
sofisticado produto oferecido ao consumo de massa? Então a fórmula
"Apocalípticos e integrados" não sugeriria a oposição entre duas atitudes
(e os dois termos não teriam valor substantivo), mas a predicação de
adjetivos complementares, adaptáveis a esses mesmos produtores de uma
'crítica popular da cultura popular'

Sobre os Apocalípticos, Eco (s.d. p.9) discorre que possuem em si uma visão elitista sobre a cultura. Ou seja, no fundo, o Apocalíptico acredita no derrocar e na catástrofe da arte por meio dos novos meios de comunicação. Para eles, existe uma comunidade de 'super-homens' capacitados a recusarem a banalidade média advinda dos novos meios culturais. Portanto, a crítica dos Apocalípticos não se pauta na crítica à cultura de massa, mas sim na disseminação da arte e da cultura para o que chamam de homem médio.

Por outro lado, o Integrado, segundo Eco (s.d. p.9), observa um alargamento na área cultural, pois, mesmo que a cultura de massa seja considerada a 'anticultura', também nasce em um período em que os bens culturais, como o rádio, o cinema, os romances populares e até mesmo as histórias em quadrinhos, estão à disposição de todos. Portanto, a perspectiva Integrada possibilita a absorção destas noções e destas informações como algo leve e agradável para o público. Assim, não seria somente um produto pronto e imposto para o público, mas, haveria o concurso dos melhores para a circulação de uma arte e de uma cultura totalmente popular. 


\title{
XI SEMINÁRIO DE PESQUISA EM CIÊNCIAS HUMANAS - SEPECH \\ Humanidades, Estado e desafios didático-científicos \\ Londrina, 27 a 29 de julho de 2016
}

Portanto, observa-se que a cultura de massa é produto de sua época. Para Eco (s.d.) existe sim uma crise no antigo sistema, se podemos dizer assim, na produção e disseminação de cultura, no entanto, seu alcance só chegará ao apogeu quando considerarmos que estes novos instrumentos estão a favor de uma humanidade modificada. Ou seja, a cultura sai do ciclo de consumo de uma elite, e, mesmo que por meio das regras do mercado, é acessível para todos independentes se esta cultura surge de cima para baixo, ou, de baixo para cima. Conforme Eco (s.d. p.34):

\begin{abstract}
Esse trecho de Fredo, no entanto, fora citado para lembrar-nos que toda modificação dos instrumentos culturais na história da humanidade, se apresenta como uma profunda colocação em crise do 'modelo cultural' precedente; e seu verdadeiro alcance só se manifesta se considerarmos que os novos instrumentos agirão no contexto de uma humanidade profundamente modificada, seja pelas causas que provocaram o aparecimento daqueles instrumentos, seja pelo uso desses mesmos instrumentos
\end{abstract}

Porém, estas modificações não estariam livres do crivo das Ciências Humanas. Tais modificações devem ser analisadas em todas as suas estruturas, tanto de produção quanto de disseminação. Portanto, nosso objetivo neste trabalho é observar por meio da perspectiva Integrada de Eco (s.d.) Palestine de Sacco como produto da Indústria Cultural.

\section{PALESTINE: UMA PERSPECTIVA INTEGRADA}

Como discutimos a pouco, a perspectiva adotada por Eco (s.d.) torna-se ampla em observar que não existe uma ruptura drástica entre aqueles que analisam a cultura de massa como negativa, e nem outra perspectiva que visa uma observação positiva. A contribuição de Eco (s.d.) oferece aos estudiosos uma contrabalança entre estas duas noções. Ao invés de propor uma ruptura, o que ocorre é a mescla entre as duas análises, ou seja, como produção humana para a humanidade, os novos meios de comunicação possuem seus pós e contras enquanto objetos de estudo.

Por meio desta perspectiva, tentaremos abordar Palestine como sendo produto desta nova forma de produzir cultura. Intitulamos como uma perspectiva Integrada por observarmos que, além de ser objeto da Indústria Cultural, e assim estar ligada às leis que regem o mercado enquanto produto, ela também está envolvida entre as táticas e estratégias que seu criador utiliza para expressar sua mensagem e poder produzir um produto consumível.

Para tanto, entendemos que estas táticas e estratégias dialogam com as noções estabelecidas por Michel de Certeau (1998). Para Certeau (1998, p.46-47), táticas tem como objetivo o outro, porém, não o apreende por inteiro, pois, trabalha com o tempo e a distância, visto que as táticas utilizadas vêem possibilidades de ganho na oportunidade. As táticas estão muito ligadas às práticas cotidianas, leitura, fazer compras e cozinhar, 


\section{SEMINÁRIO DE PESQUISA EM CIÊNCIAS HUMANAS - SEPECH \\ Humanidades, Estado e desafios didático-científicos \\ Londrina, 27 a 29 de julho de 2016}

portanto, entendemos como táticas para a produção de Palestine, situações que vão desde as leituras de Sacco até a preparação de seus desenhos.

Por outro lado, observaremos também as estratégias, que para Certeau (1998, p.46) são à base de gestão na produção do material cultural. Ao contrário da tática, ela não é oportunista, mas sim calculada, espera-se um resultado prévio em sua atitude. Por exemplo, a mensagem parcial de Sacco em seus quadrinhos, designa a estratégia utilizada por ele, ou seja, como veremos adiante, sua mensagem é parcial à causa palestina, e assim, por meio de seus desenhos e de seu discurso, é utilizado uma dinâmica de estratégias para repassar sua mensagem a seus leitores.

Portanto, por meio das táticas e estratégias, tentaremos em nosso trabalho observar as características da perspectiva Integrada no trabalho de Sacco enquanto produto da Indústria Cultural. Seu fator mercadológico e ideológico será observado dentro do processo de produção de seu trabalho, e não sobre o consumo de seus leitores, assim sendo, a escolha pela perspectiva Integrada supre neste trabalho como base de nossa hipótese.

I

Palestine é o trabalho do jornalista estadunidense Joe Sacco. Sacco nasceu em Malta, no ano de 1960, no entanto, muito jovem foi morar com os pais nos Estados Unidos, onde cursou jornalismo pela Universidade do Óregon em 1981. Devido à falta de oportunidade no campo jornalístico, resolve por conta própria viajar o mundo em 1988. No entanto, em 1981, começa seu interesse pela causa palestina, conforme José Arbex Jr (2011, p.xiii) “Ele mesmo começou a se interessar pela 'questão palestina' a partir de 1981, quando Israel bombardeou o Líbano". Porém, viaja à Palestina somente em dezembro de 1991, quando ainda aconteciam os últimos resquícios da Primeira Intifada Palestina de 1987.

Durante os dois meses que permaneceu entre os palestinos, coletou entrevistas em várias residências, hospitais, escolas e até mesmo em organizações não governamentais na Cisjordânia e na Faixa de Gaza. De forma estratégica, os locais escolhidos fazem parte dos territórios ocupados por Israel após 1967, locais considerados como o epicentro da Intifada. Sua viagem durou dois meses, tendo seu término em janeiro de 1992, de onde saiu da Palestina e se dirigiu para a Bósnia, onde também realizou um trabalho bem parecido com Palestine. Em 1993, Sacco retorna aos Estados Unidos e inicia a publicação de Palestine, que se estende até 1995, em nove volumes com publicações periódicas.

Como observamos acima, Sacco se dirige para a Palestina em 1991. Porém, qual o motivo que o levou a seguir viagem para o conflito três anos após os momentos iniciais? Outra questão, porque seguiu viagem para a Bósnia e não retornou para os Estados Unidos para publicar seu trabalho, visto que Sacco descreve o orçamento apertado que tinha no momento da viagem? Pois, apesar de Arbex Jr (2011,p.xiii) afirmar que desde 1981, Sacco tem interesse pela causa palestina, e, tendo o conflito iniciado em 1987, o jornalista posterga por três anos sua ida aos territórios ocupados.

Em dezembro de 1987, teve início nos territórios ocupados por Israel, após a Guerra de 1967, o movimento popular palestino contra a repressão das Forças de Defesa de Israel (FDI). Segundo André Gattaz (2003, p.167): 


\section{SEMINÁRIO DE PESQUISA EM CIÊNCIAS HUMANAS - SEPECH \\ Humanidades, Estado e desafios didático-científicos \\ Londrina, 27 a 29 de julho de 2016}

A manutenção do regime de ocupação israelense e a ineficiência da OLP em solucionar os graves problemas da população palestina levaram à revolta conhecida como Intifada. Após algumas semanas de manifestações espontâneas e desorganizadas, os grupos políticos e paramilitares surgidos nos territórios ocupados começam a dar direção aos protestos, durante reprimidas por Israel. Em conseqüência da Intifada, a OLP decidiu voltar com mais vigor à cena política, sendo, entretanto levada pelo governado norte-americano a participar de negociações bilaterais com Israel, no que veio a ser conhecido como 'processo de paz de Oslo' - uma série de acordos que sedimentava o controle israelense sobre os territórios ocupados, criando a ilusão de paz e de um Estado palestino

Assim sendo, entre 1987 e 1993, quando foi realizado o processo de paz de Oslo, é considerado o recorte temporal que corresponde a Primeira Intifada da Palestina. A partir deste ponto de vista, dentro deste período, temos a primeira impressão que o movimento popular poderia ter tido certo grau de intensidade durante estes seis anos. Não obstante, a chegada de Sacco se daria em um período de grande intensidade de movimentação entre a FDI e a população palestina. Por outro lado, a análise de Gattaz (2003, p.179) nos faz problematizar sobre algumas estratégias que permeiam a produção de Palestine:

Como resultado do engajamento dos tunisianos (OLP) nas negociações de paz, da repressão às lideranças palestinas locais, e das punições coletivas impostas à população civil palestina pelo Exército de Israel, o ímpeto da Intifada foi decaindo, e no início de 1991 a revolta estava praticamente esgotada (ao menos enquanto movimento de massas; a violência de parte a parte resistiu com certa intensidade por mais dois anos, razão pela qual alguns autores consideram que a Intifada estendeu-se até 1993

Conforme a análise de Gattaz (2003) sobre o recorte histórico da Intifada, o caráter popular do conflito já havia exaurido. Ou seja, em sua chegada à Palestina em dezembro de 1991, o conflito já se encontrava em seus momentos finais, e já havia grande participação por parte da Organização pela Libertação da Palestina (OLP). Tanto que, Sacco registra, entre suas 285 páginas, somente um momento de conflito entre palestinos e israelenses em sua passagem a Ramallah (SACCO, 2011, p.119). Não que as restrições e prisões tivessem tido seu fim, porém, seu trabalho não apresenta uma cobertura de "furo" jornalístico, mas de coleta de entrevistas com testemunhas oculares do conflito. Portanto, sua estratégia inicial pode ter sofrido algumas alterações no que permeiam sua produção.

Independente da escolha entre um "furo" jornalístico ou a coleta de entrevistas, não tira o caráter diferenciado do trabalho de Sacco. Um dos diferenciais do seu trabalho fica a cargo da inserção dos quadrinhos em um trabalho jornalístico. Ao contrário de Adorno (2009, p.14) que visualiza a Indústria Cultural como absolutizadora da imitação, Palestine apresenta seus traços de modificação. Em comparação com o premiado trabalho de Art Spielgman (2009) Maus, no qual Spielgman (2009) coleta os registros de seu pai sobrevivente do campo de concentração nazista de Aushwitz, o trabalho de Spielgman (2009), também considerado como jornalismo em quadrinhos, Sacco diferencia-se em 


\section{SEMINÁRIO DE PESQUISA EM CIÊNCIAS HUMANAS - SEPECH \\ Humanidades, Estado e desafios didático-científicos \\ Londrina, 27 a 29 de julho de 2016}

coletar várias entrevistas, e também permanece o caráter anônimo de suas personagens, ao contrário de Spielgman (2009), que delimita muito bem as suas, como seu pai e sua mãe. A influência de Spielgman (2009) é explicita, tanto que, nas primeiras páginas de $O$ Derrotista (2006) do próprio Sacco, conforme figura 1, no canto direito entre seus livros, encontramos referência à leitura de Maus por meio de um desenho de sua prateleira de livros, no qual deixa em negrito o título da obra de Spielgman (2009).

Por outro lado, Palestine tem suas várias peculiaridades em contraste a Maus. O que podemos afirmar como sendo uma "imitação", ficaria restrita ao campo do estilo narrativo escolhido, ou seja, o jornalismo em quadrinhos. Porém, para a produção deste estilo, estaríamos restritos a formação de outros jornalistas com algum talento para o desenho, o que nos levaria a pensar no campo da coincidência ou dos acasos. Outro ponto de convergência entre os dois trabalhos são as influências no estilo artístico. Maus apresenta uma metáfora entre as etnias representadas. Por exemplo, os alemães nazistas são gatos, os judeus ratos, os poloneses porcos e os estadunidenses como cachorros. Palestine tem seu estilo mais realista, e adaptado ao estilo de desenho das revistas undergrounds estadunidense.

Apesar de afirmar que seu estilo é o bigfoot (SACCO, 2011, p.xvii), ou pé grande,

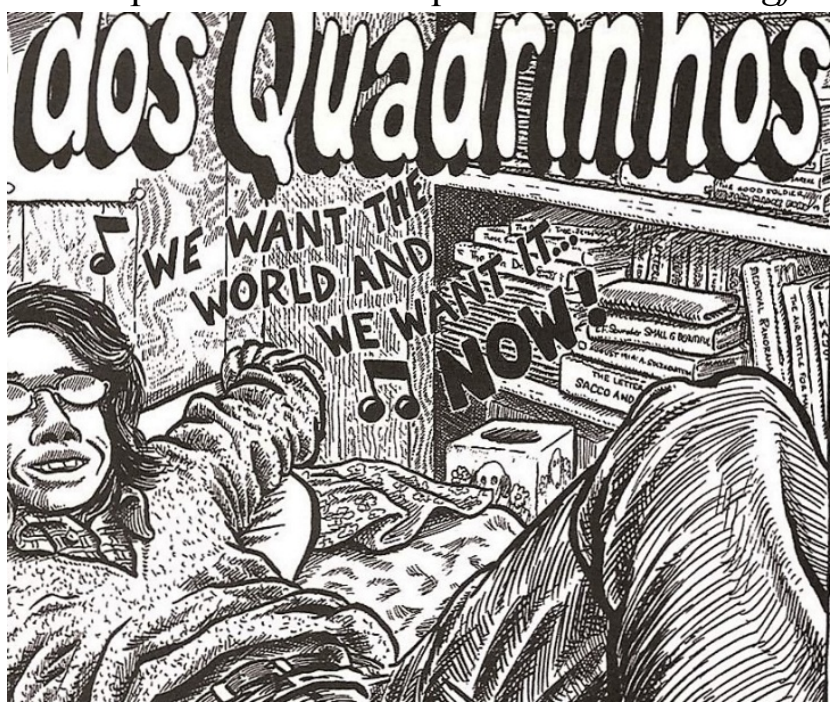

Figure 1:SACCO, 2006 p.1 que consiste na derivação dos desenhos animados da década de 1930 (MAZUR e DANNER, 2014 p.26-27), o estilo de Sacco está muito mais voltado para os clássicos quadrinhos de humor sombrio e transgressor da editora EC Comics da década de 1950. Porém, qual o motivo em classificar seus desenhos como bigfoot e não diretamente sobre a influência undergrond da editora EC Comics? Talvez tal situação seja uma estratégia para aceitação do seu público. As revistas undergrounds sofreram grande repressão na década de 1970 , ainda mais após a decisão da

Suprema Corte dos Estados Unidos possibilitarem que as comunidades locais pudessem estabelecer seus padrões de obscenidade (MAZUR e DANNER, 2014 p.40), o que levou ao fim do movimento underground dos quadrinhos nos Estados Unidos.

Portanto, na tentativa de apresentar um trabalho com características que não $o$ comprometessem, e que possa abranger um maior número de leitores, a escolha na determinação do estilo artístico pode ter influência nas palavras de Sacco. Assim sendo, escolher o estilo, ou neste caso, determinar em dizer qual é o seu estilo de desenho está relacionado à estratégia mercadológica, ou seja, caso determine que seu estilo estivesse integrado aos trabalhos undergrounds, poderia ocorrer uma negação maior pelo trabalho, 


\section{SEMINÁRIO DE PESQUISA EM CIÊNCIAS HUMANAS - SEPECH \\ Humanidades, Estado e desafios didático-científicos \\ Londrina, 27 a 29 de julho de 2016}

visto que, dentro dos Estados Unidos, já trabalha com um assunto delicado pela opinião pública.

Ainda na esfera das táticas e estratégias na produção de Palestine, a edição brasileira apresenta um pequeno recorte no qual Sacco apresenta algumas alterações realizadas por ele durante o processo de arte finalização. Conforme Eisner (2010, p.1):

As histórias em quadrinhos comunicam uma "linguagem" que se vale da experiência visual comum ao criador e ao público. É de se esperar dos leitores modernos uma compreensão fácil da mistura imagem-leitura e da tradicional decodificação de texto. A história em quadrinhos pode ser chamada "leitura" num sentido mais amplo que o comumente aplicado ao termo

Como podemos observar a relação entre criador e leitor, dentro da produção dos quadrinhos, está intimamente ligada. Existe uma comunicação expressa por meio da experiência visual entre o leitor e o criador. A linguagem dos quadrinhos não fica restrita somente a requadros nos quais estão inseridos imagens misturadas a palavra escrita. $\mathrm{O}$ sucesso de um trabalho quadrinístico é dependente desta relação. Pois, cabe ao criador expressar uma linguagem fluída ao seu leitor, entre elas, manipulação da passagem do tempo por meio do tamanho de requadros, a fonte da palavra escrita para cada situação em particular (negrito para frases de impacto e tremuladas para momentos de tensão).

Esta relação entre criador e leitor que permeia a produção das histórias em quadrinhos leva Sacco a repensar sobre a fabricação de um trecho de seu trabalho. Conforme as figuras 3, 4 e 5, observamos que Sacco altera de última hora as páginas $200 \mathrm{e}$ 201. Sobre a mudança, Sacco (2011, p.xxvi) confirma que:

Acredito que minha primeira tentativa de representar soldados israelenses brutalizando um jovem paciente na p.200 e início da p.201 foi um tanto excessiva, $\mathrm{O}$ grande painel de abertura, apesar de adequado em termos de composição, se sobrepunha ao restante da página, e a sequência de meia página em que os rostos gritando dissolvem em um buraco negro me pareceu artificial demais. Optei por uma narrativa mais direta, que usa movimentos rápidos de olho, enquadramentos bem próximos e longas legendas para carregar a cena

Sobre sua afirmação, podemos levantar a hipótese se houve ou não a interferência do editor no peso excessivo de violência na primeira proposta apresentada por Sacco. Pois, como os Estados Unidos apoiam indiretamente o Estado de Israel, tais cenas poderiam não ser tão bem recebidas por alguns leitores. Ainda sobre tal hipótese, Palestine é uma revista publicada periodicamente. Entre 1993 a 1995, foram publicados nove números. Conforme a lógica da edição especial, no qual reúne os nove exemplares em um encadernado, ao levarmos em consideração que ela possui nove capítulos, cada um seria um periódico avulso. As figuras 3 e 4, que correspondem respectivamente às página 200 e 201, em contraposição à figura 5 , que representa a primeira versão proposta, estaria inserida na 


\section{SEMINÁRIO DE PESQUISA EM CIÊNCIAS HUMANAS - SEPECH \\ Humanidades, Estado e desafios didático-científicos \\ Londrina, 27 a 29 de julho de 2016}

publicação de número 7 , por outro lado, outras cenas de violência, ou sobre seu resultado estão dispostas em número anteriores. Por exemplo, ao observamos a figura 2 , verifica-se um homem em seu leito, no qual, Sacco faz questão de expressar bem sua dor. Tal imagem está na página 32, o que corresponderia ao periódico de número 2 .

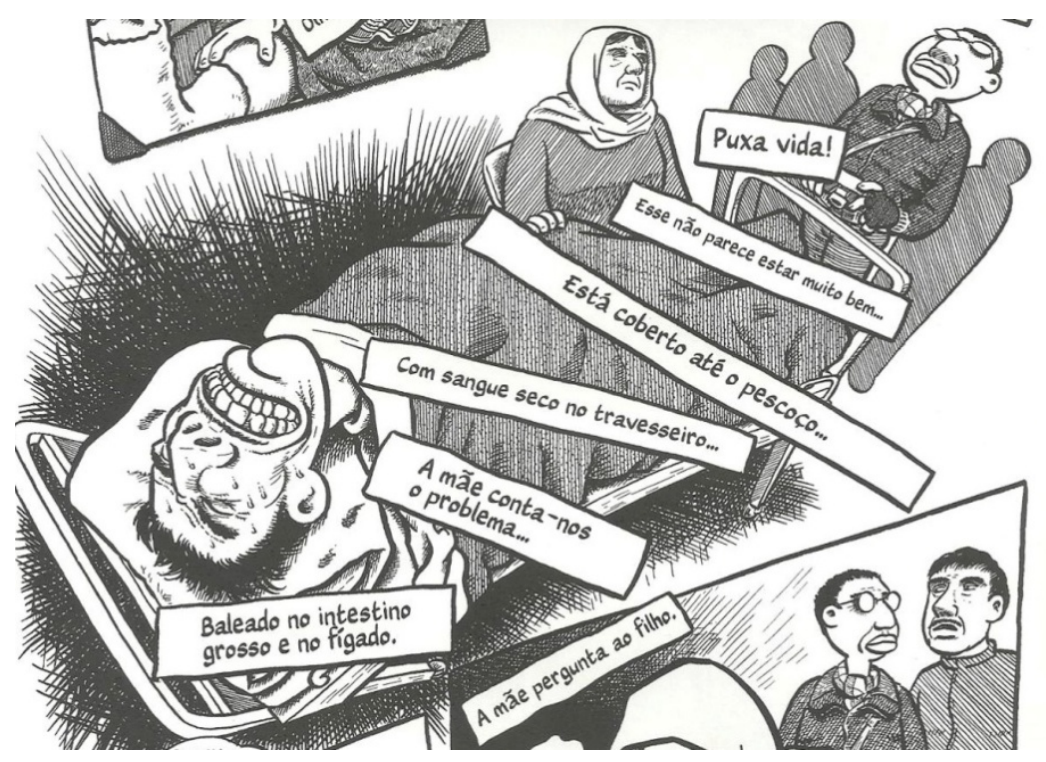

Figure 2:SACCO, 2011 p.32

Como podemos observar, em contraste com a primeira tentativa de representar a cena de agressão do jovem palestino para a segunda versão, e a definitiva, Sacco opta em manipular o requadro e a passagem do tempo inserido no contexto. Devemos entender que, "A leitura da história em quadrinhos é um ato de percepção estética e de esforço intelectual" (EISNER, 2010 p.2), assim, ao manipular a quantidade de requadros e seu tamanho, Sacco suaviza as cenas de violência para a primeira versão. Ao desenhar os requadros sem nenhum resquício de diálogo, Sacco evoca a experiência comum do seu leitor, ou seja, permite que o leitor retire da seqüência de imagens a sua própria conclusão, No entanto, esta estratégia também é encontrada na primeira versão. 
XI SEMINÁRIO DE PESQUISA EM CIÊNCIAS HUMANAS - SEPECH

Humanidades, Estado e desafios didático-científicos

Londrina, 27 a 29 de julho de 2016

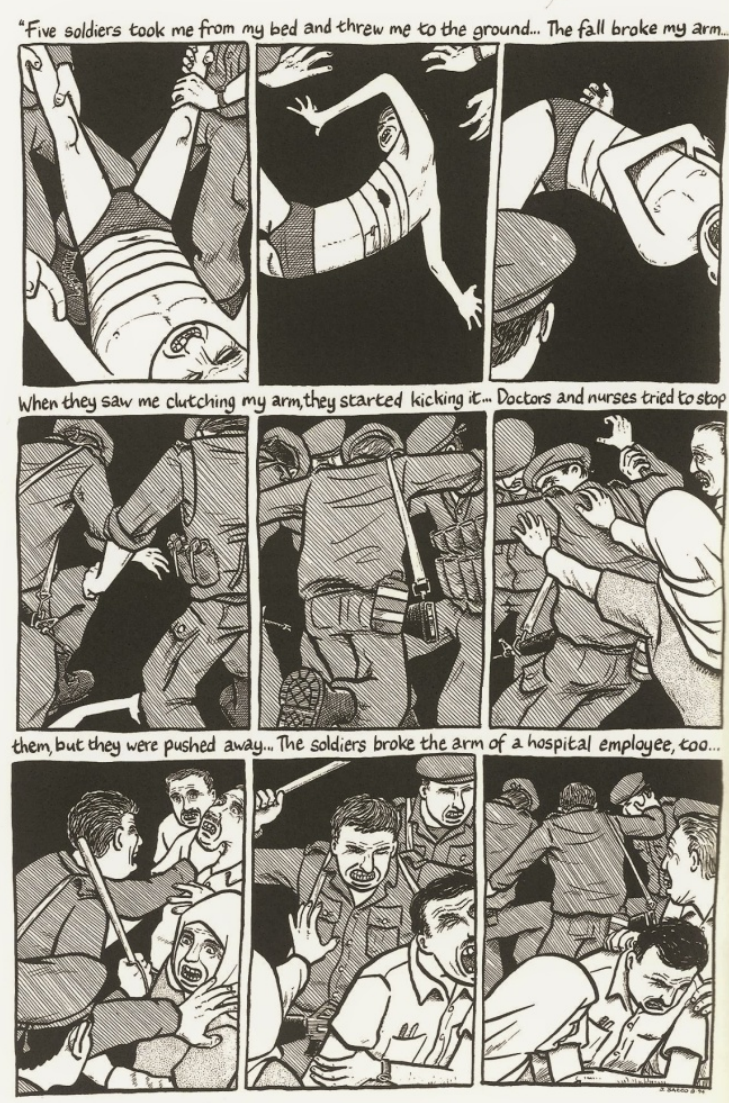

500

Figure

3: $\quad$ SACCO, 2014

p. 200 


\section{SEMINÁRIO DE PESQUISA EM CIÊNCIAS HUMANAS - SEPECH \\ Humanidades, Estado e desafios didático-científicos \\ Londrina, 27 a 29 de julho de 2016}

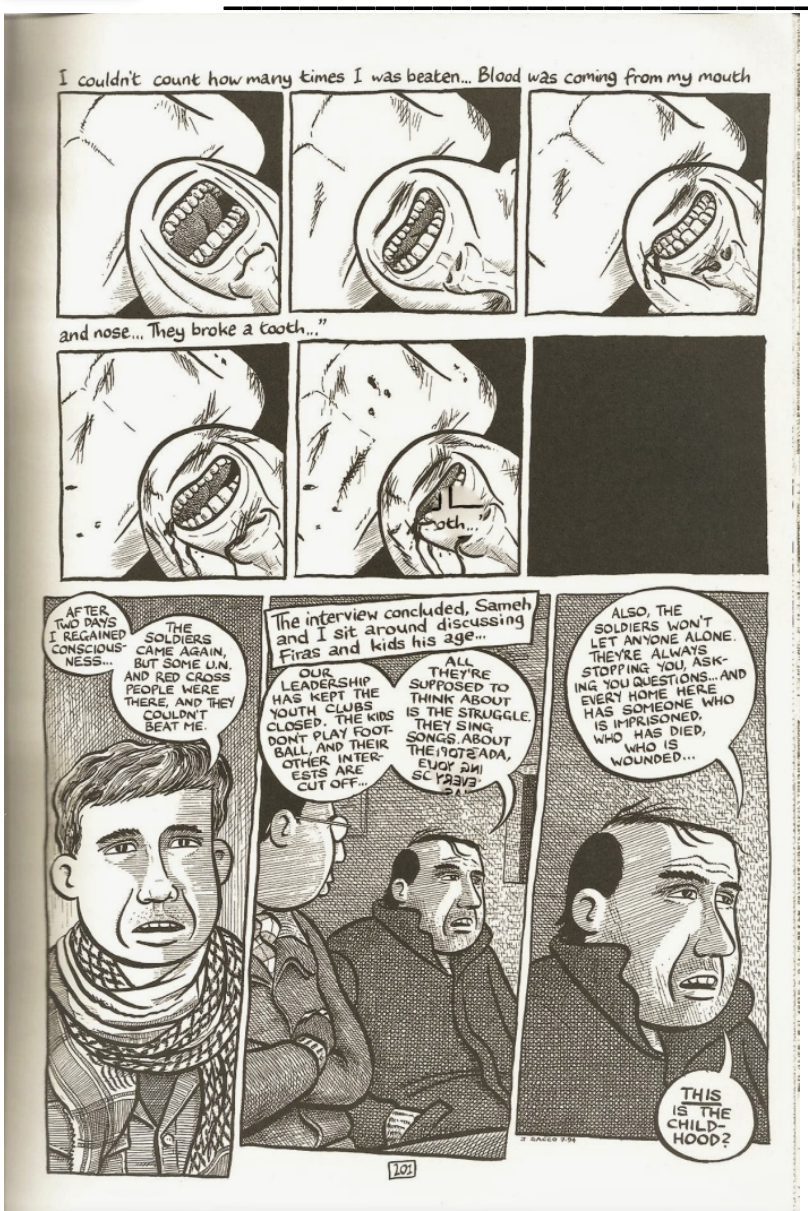

Figure 4: SACCO, 2014, p.201

A primeira observação que podemos fazer está relacionada com a quantidade de requadros. A diminuição na quantidade de requadros que representam o jovem palestino, junto ao aumento no tamanho dos requadros, é um artifício para a diminuição do tempo corrente. Ou seja, quanto maior o número de requadros com tamanhos reduzidos significa para a produção dos quadrinhos, maior velocidade das ações ocorridas. Portanto, entre a primeira versão, e a versão definitiva, podemos observar a diminuição na quantidade de requadros e o aumento em seu tamanho, o que possibilitaria ações lentas e graduais. Por este ponto de vista, Sacco estrategicamente diminuiu as ações de violência ao manipular estes artifícios de produção dos quadrinhos. 


\section{SEMINÁRIO DE PESQUISA EM CIÊNCIAS HUMANAS - SEPECH \\ Humanidades, Estado e desafios didático-científicos \\ Londrina, 27 a 29 de julho de 2016}

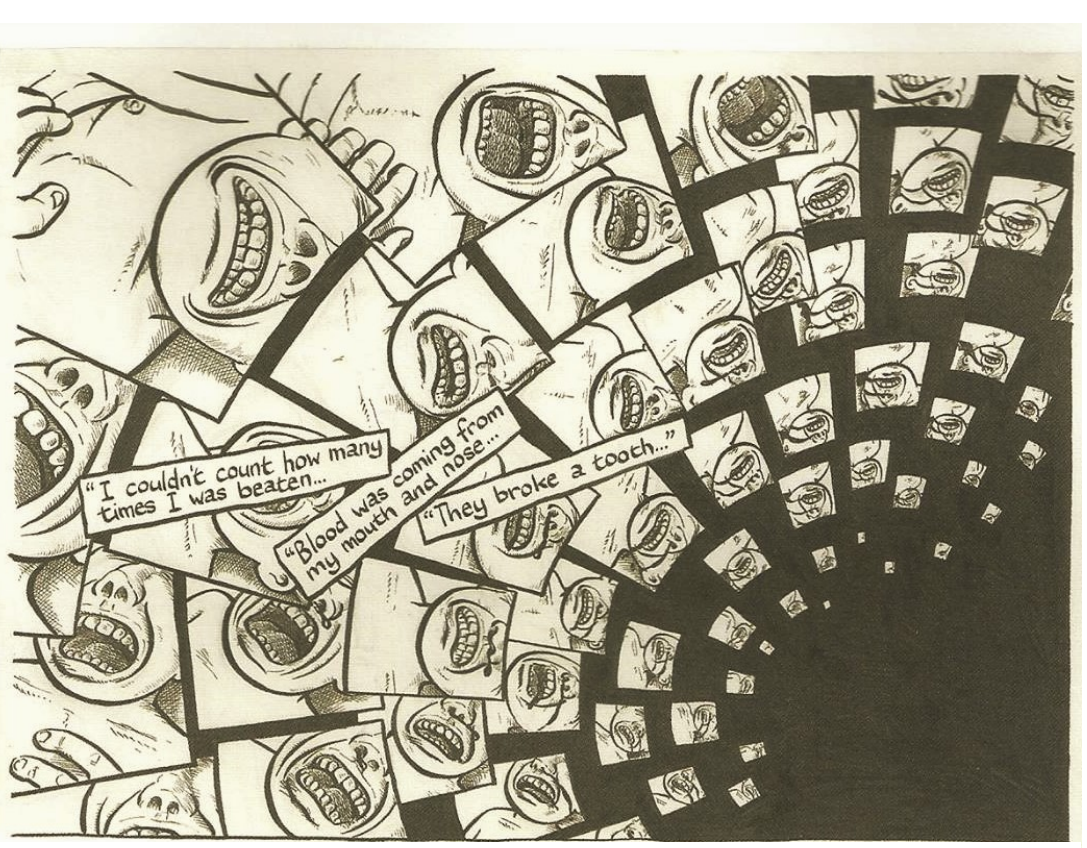

Figure 5:SACCO, 2011 p.xvii
Manipular a composição do requadro é outro recurso utilizado por Sacco. Para Eisner (2010, p.90) a manipulação do requadro é comparada a uma cena teatral. Funciona como um palco, o quadrinho tem a função de controlar o ponto de vista do leitor e de estabelecer a perspectiva do campo de visão que a imagem é vista. Esta manipulação permite ao criador estabelecer

as bases dos fatos e acontecimentos da ação, além de estimular e orientar as emoções do leitor. Portanto, ao organizar lado a lado as imagens, como na versão definitiva, ao invés de colocar vários requadros espalhados na página, Sacco teve como objetivo diminuir a quantidade de cenas de violência sofridas pelo jovem palestino.

Portanto, tal estratégia pode estar associada a possíveis críticas nos números iniciais de Palestine, pois, ao discutir o conflito entre Israel e Palestina dentro de um dos países com a maior colônia de judeus fora de Israel, poderia levantar alguns desafetos sobre a produção cultural de Palestine. Em seus relatos a edição brasileira, nenhuma crítica é tecida por parte de algum israelense sobre seu trabalho, no entanto, Sacco cita a crítica de um palestino sobre seu estilo ao representar o povo árabe (SACCO, 2011 p.xvii), ou seja, podemos considerar que Sacco leva em conta as críticas durante a publicação de cada número, pois, faz questão de esclarecer na edição especial o mal estar causado pela forma que representou o povo árabe em seu trabalho, pois, conforme suas palavras "Meu desenho não tinha a intenção de desrespeitar árabes ou judeus: era o estilo com o qual eu desenhava pessoas naquela época" (SACCO, 2011 p.xvii).

No entanto, a maior crítica sofrida por Palestine, e confessada por Sacco, refere-se à parcialidade do seu trabalho. Segundo Sacco (2011, p.xvii), "A mais séria crítica à Palestina foi de que contei apenas um lado do conflito palestino-israelense". Devido às várias leituras, realizadas de forma tática por ele, que teve início a partir de 1981, entre Noam Chomsky (2013) a Edward Said (2012), Sacco não esconde sua parcialidade pela causa palestina contida no resultado de seu trabalho. Um dos motivos apontados por ele advém da vergonhosa cobertura jornalística que seus colegas de trabalho realizavam sobre o conflito (SACCO, 2011 p.xvi). Tais críticas são também compartilhadas por Said (2012) e Chomsky (2013). Para Said (2012, p.164), seu olhar sobre a mídia tem um pequeno grau 


\section{SEMINÁRIO DE PESQUISA EM CIÊNCIAS HUMANAS - SEPECH \\ Humanidades, Estado e desafios didático-científicos \\ Londrina, 27 a 29 de julho de 2016}

de positividade, por analisar que a partir de 1967, há uma mudança no quadro sobre o conflito, no entanto, não deixa de criticá-la ao dizer que a mídia de massa ainda tem seu caráter persuasivo, que provavelmente disseminou a visão do palestino terrorista. Por outro lado, Chomsky (2013, p.14-15) postula a teoria de Walter Lipmann sobre a construção do consenso, ou seja, a função da mídia é conduzir um rebanho desorientado e alienado.

O contato com as leituras de Chomsky (2013) e Said (2012) tornam-se taticamente a observação de mundo de Sacco sobre o conflito. Como afirma em seu trabalho, "Minha posição foi e ainda é que a visão do governo israelense já está bem representada pela grande mídia norte-americana, e é calorosamente defendida por quase todo político eleito para altos cargos nos Estados Unidos" (SACCO, 2011 p.xvii). Portanto, ao contrário da grande mídia de massa, Sacco tenta problematizar a questão que envolve a Palestina e Israel, e assim, possibilitar a seus leitores a perspectiva palestina, e não a israelense, já muito bem defendida nos Estados Unidos. Pois, conforme Burke (2004, p.24), é imprudente atribuirmos aos artistas repórteres um "olhar inocente", livre de expectativas e totalmente objetivo, literalmente e metaforicamente, eles esboçam um "ponto de vista" dentre vários outros sobre o assunto. Assim sendo, a parcialidade de Sacco corresponde ao seu ponto de vista, neste caso, taticamente estruturado pelas escolhas de leitura que realizou nos anos que precedem sua viagem.

Por conseguinte, ao dialogarmos com a noção de tática e estratégia de Certeau (1998), podemos observar Palestine inserida dentro da perspectiva Integrada de Eco (s.d.) sobre a Indústria Cultural. Não podemos descartar seu caráter mercadológico e ideológico. Porém, por meio de uma análise Integrada, permitiu-nos observar os processos estratégicos que estão por trás de sua produção e as práticas cotidianas de leitura de Sacco como táticas que o levaram a produzir um trabalho que parcialmente se distingue da cobertura já exercida sobre o conflito.

\section{CONSIDERAÇÕES FINAIS}

No decorrer do trabalho, observamos que para Eco (s.d.) a Indústria Cultural é uma forma de expressão cultural da sociedade capitalista atual. Portanto, não deve ser analisado somente pelo viés negativo, ou, como denominado por ele, Apocalíptico. Por outro lado, como observadores com uma perspectiva positiva, os integrados possibilitam observar pontos positivos da Indústria Cultural. Ainda sobre sua análise, não podemos deixar de observar que Apocalípticos e Integrados não significam uma clivagem, mas sim, uma mescla de pontos de vista para estudarmos a produção e as conseqüências da Cultura de Massa.

Por meio desta perspectiva Integrada, tentamos observar a produção de Palestine do jornalista estadunidense Joe Sacco, está inserido por várias práticas, como suas leituras sobre o conflito, e estratégias, como a escolha de sua parcialidade a causa palestina. Assim sendo, estas táticas e estratégias estão ocultas nas entrelinhas de seu trabalho. Reconhecer estas táticas e estratégias inseridas no processo de produção nos ajuda a observar outra 


\section{SEMINÁRIO DE PESQUISA EM CIÊNCIAS HUMANAS - SEPECH \\ Humanidades, Estado e desafios didático-cientificos \\ Londrina, 27 a 29 de julho de 2016}

perspectiva sobre a produção dos produtos da Cultura de Massa, e assim, analisar que tais produtos não são somente alienadores para seus consumidores.

Compreender a relação do criador e o leitor é outra estratégia, dentre tantas outras possíveis de serem observadas em Palestine. A análise desta estratégia nos permite observar que para o sucesso de uma história em quadrinhos não depende somente do criador, mas, em sua empatia com seu leitor. Ao descartar tal relação, o criador de histórias em quadrinhos pode se tornar um fracasso mercadológico, ainda mais se tratando de uma história publicada em várias edições. Portanto, ao considerar que o leitor tem papel fundamental no processo de produção, as estratégias podem ser modificadas, para que continue a manter a vendagem para seus leitores.

\section{REFERÊNCIAS BIBLIOGRÁFICAS}

ADORNO, Theodor. Indústria Cultural e sociedade. São Paulo: Paz e Terra, 2009. ARBEX JR. José. Prefácio. In: SACCO, J. Palestina. São Paulo, Conrad Editora do Brasil, 2011

BURKE, Peter. Testemunha ocular: história e imagem - Bauru, SP:EDUSC, 2004. CERTAU, Michel de. A invenção do cotidiano: Artes de fazer. 3.ed. Petrópolis: Editora Vozes, 1998.

CHOMSKY, Noam. Mídia: propaganda política e manipulação. São Paulo: Editora WMF Martins Fontes, 2013

ECO, Umberto.Apocalipticos e Integrados. São Paulo: Editora Perspectiva, [s.d]

EISNER, Will; Quadrinhos Arte Sequencial princípios básicos e práticos do lendário cartunista. 4.ed. São Paulo, SP; Editora WMF Martins Fontes, 2010.

GATTAZ, André Castanheira. A guerra da Palestina: da criação do Estado de Israel à Nova Intifada. São Paulo: Usina do Livro, 2003.

SACCO, Joe. O Derrotista. São Paulo, Conrad Editora do Brasil, 2006. , Joe. Palestina. São Paulo, Conrad Editora do Brasil, 2011. , Joe. Palestine. Seatle: Fantagraphics Books, 2014.

SAID, Edward W. A questão da Palestina. São Paulo, SP: Unesp, 2012.

SPIELGMAN, Art. Maus, São Paulo: Companhia das Letras, 2009. 